\title{
Fluorescence anisotropy of acridinedione dyes in glycerol: Prolate model of ellipsoid
}

\author{
V K INDIRAPRIYADHARSHINI ${ }^{\mathrm{a}}$ and P RAMAMURTHY ${ }^{\mathrm{a}, \mathrm{b}, *}$ \\ ${ }^{a}$ National Centre for Ultrafast Processes, University of Madras, Taramani Campus, Chennai 600113 \\ ${ }^{\mathrm{b}}$ Department of Inorganic Chemistry, University of Madras, Guindy Campus, Chennai 600025 \\ e-mail: prm60@hotmail.com
}

\begin{abstract}
Time-dependent reorientations of resorcinol-based acridinidione (ADR) dyes in glycerol were studied using steady-state and time-resolved fluorescence studies. The difference between fluorescence anisotropy decays recorded at $460 \mathrm{~nm}$ when exciting at $250 \mathrm{~nm}$ and those obtained when exciting at $394 \mathrm{~nm}$ are reported. When exciting at $394 \mathrm{~nm}$, the fluorescence anisotropy decay is bi-exponential, while on exciting at $250 \mathrm{~nm}$ a mono-exponential fluorescence anisotropy decay is observed. We interpret this in terms of different directions of the absorption dipole at 394 and $250 \mathrm{~nm}$ with the emission dipole respectively, which is experimentally validated and further analysed as a prolate model of ellipsoid.
\end{abstract}

Keywords. Fluorescence anisotropy; prolate model; acrydinedione dyes.

\section{Introduction}

Rotational dynamics of solutes in solvents have received much attention over the years. ${ }^{1}$ A solute in different electronic states could have markedly different polarization decay processes in the same solvent. $^{2}$ The anisotropic rotational behaviour of small molecules has been observed with the aid of several experimental techniques ${ }^{3-6}$ and considerable interest is shown in modelling the molecules. Reorientation times for moderate molecular sizes have been reported $^{7-14}$ using picosecond laser technique. Eisenthal and Drexhage ${ }^{15}$ reported the first direct observation of rotational reorientation of molecules in liquid solution using picosecond laser pulses.

A fluorophore in different environments is subjected to different depolarising processes. ${ }^{16} \mathrm{~A}$ recent study $^{17}$ of fitting in nine kinetic models also describes a system with two fluorescent species and two depolarising processes. Truong et $a l^{18}$ have recently developed a technique used to measure the rotational dynamics of solutes in ground and excited states using optical pump/probe method. Previous findings suggest that molecules like perylene and 9aminoacridine represent the extremes of rotational behaviour. ${ }^{10,16}$ Barkley et $a l^{16}$ have studied planar molecules like perylene and 9-aminoacridine in glycerol at various temperatures. The rotational dy-

*For correspondence namics of perylene are consistent with those of a disk with slip boundary conditions and that of the rotation of 9-aminoacridine are interpreted as those of prolate ellipsoid of revolution. Recently, Kunz and coworkers ${ }^{19}$ have used fluorescence anisotropy method to probe the size of the micelle. The fluorophores used to determine the size of the micelle were acridine orange, ${ }^{20}$ octadecylrhodamine $\mathrm{B}^{21}$ Kunz and coworkers ${ }^{19}$ showed that the tetraphenylporphyrin dye with four di(isopropyleneglycol) methylether residues is the first fluorophore that shows single exponential decay both in fluorescence intensity and anisotropy in spherical micelle solution.

In the present study, we used resorcinol-based acridinedione (ADR) dyes with substitution as shown below. For all these dyes, the central ring adopts a boat conformation and the outer rings adopt the sofa conformation. ${ }^{23}$<smiles>[R]N1C2=C(CC3=C1CCCC3=O)C(=O)CCC2</smiles>

\begin{tabular}{|c|l|}
\hline ADR & \multicolumn{1}{|c|}{$\mathbf{R}$} \\
\hline $\mathbf{1}$ & $-\mathrm{H}$ \\
\hline $\mathbf{2}$ & $-\mathrm{CH}_{3}$ \\
\hline $\mathbf{3}$ & $-\mathrm{C}_{6} \mathrm{H}_{5}$ \\
\hline $\mathbf{4}$ & $-\mathrm{C}_{6} \mathrm{H}_{4}\left(p-\mathrm{CH}_{3}\right)$ \\
\hline $\mathbf{5}$ & $-\mathrm{C}_{6} \mathrm{H}_{4}(p-\mathrm{Cl})$ \\
\hline
\end{tabular}

ADR-based dyes have been developed as a family of efficient laser dyes. ${ }^{23}$ These dyes have structural similarity with NADH. These dyes have been shown 
to mimic NADH analogues to a great extent because of their tricyclic structure, which is capable of protecting the enamine moiety. ${ }^{24}$ These dyes function both as electron donors and acceptors and electrochemical, ${ }^{25}$ photophysical ${ }^{26}$ excited state reaction ${ }^{27}$ and inclusion behaviour ${ }^{28}$ have been investigated. The first non-conjugated bi-chromophoric system that shows dual fluorescence with an enhancement in the fluorescence intensity in the presence of transition metal ions has been studied. ${ }^{29}$

In the present work, we report the fluorescence anisotropy decay of ADR dyes in glycerol and its dependence on temperature at two excitation wavelengths, at which the dipole directions are different.

\section{Experimental}

ADR (1-5) dyes were synthesised by the procedure reported in the literature. ${ }^{23}$ Glycerol used was AR grade as obtained from Qualigens, India. Absorption spectra were recorded using an Agilent 8453 diode array spectrophotometer. The excitation anisotropy spectra were recorded using a Fluoro Max 2, ISA Jobin-Yvon-Spex Instruments, S.A. Inc., USA. Fluorescence emission and emission anisotropy spectra were recorded using a Perkin-Elmer MPF44B spectrofluorimeter interfaced with a PC through RISHCOM-100 multimeter and with the sheet polariser at the excitation and emission pathway. The fluorescence anisotropy is given by the following equation,

$$
r=\frac{I_{\|}-G I_{\perp}}{I_{\|}+2 G I_{\perp}},
$$

where $I_{\|}$and $I_{\perp}$ are the intensities observed with the emission polariser parallel or perpendicular to the polarised excitation, respectively. The $G$ factor is the ratio of the intensity $\left(I_{\|} / I_{\perp}\right)$ observed with horizontally polarised excitation. ${ }^{30}$

Time-resolved fluorescence decays were recorded using time-correlated single-photon counting (TCSPC) technique. A diode pumped millennia $\mathrm{V} \mathrm{CW}$ laser (Spectra Physics, $532 \mathrm{~nm}$ ) was used to pump the Ti: sapphire rod in a picosecond mode-locked laser system (TSUNAMI, Spectra Physics) operated at $82 \mathrm{MHz} .750$ and $788 \mathrm{~nm}$ served as the fundamental wavelengths from the $\mathrm{Ti}$ : sapphire laser and were passed through the pulse picker (Spectra Physics
$39802 \mathrm{~S}$ ) to pick out $4 \mathrm{MHz}$ pulses. The corresponding second $(394 \mathrm{~nm})$ and third $(250 \mathrm{~nm})$ harmonics were used for the excitation of the sample. Samples were excited through the Glan-Thompson polariser oriented in vertical and horizontal directions. The photons emitted from the sample are detected by a high gain Hamamatsu Micro Channel Plate Photomultiplier tube (R 3809U MCP-PMT). In these experiments, the fluorescence emission was collected at the magic angle $\left(54.7^{\circ}\right)$ and analysed by the reconvolution method using an iterative least squares method. ${ }^{31}$

The fluorescence decay $I(t)$ was analysed using an exponential function given by,

$$
I(t)=B \exp \left(-t / \tau_{f}\right)
$$

where $B$ and $\tau_{f}$ are preexponential factors and the lifetime of the fluorophore respectively. The goodness of the fit depends upon the $\chi^{2}(\chi$ square $)$ values and the distribution of the weighted residuals.

The fluorescence anisotropy decay $r(t)$ was obtained from,

$$
r(t)=B_{1} \exp \left(-t / \tau_{r 1}\right)+B_{2} \exp \left(-t / \tau_{r 2}\right),
$$

where $\left(B_{1}+B_{2}\right)=r_{0}$ is the fundamental anisotropy and $\tau_{r}$ is the rotational correlation time. The instrument response function required in the fitting procedure was obtained by substituting the sample with the ground glass scatterer.

A sequential method for the analysis of fluorescence anisotropy decay is the direct analysis from the data. This method makes use of the decay curve $I_{\|}$and $I_{\perp}$ together with the $G$ factor, to calculate the fluorescence anisotropy decay point by point. For each set of data points a sum curve $\left(I_{\|}+2 G I_{\perp}\right)$ and difference curve $\left(I_{\|}-G I_{\perp}\right)$ is constructed and the $r(t)$ curve so obtained can then be analysed using any of the exponential fit programs in terms of number of exponential decay components; subtle errors due to convolution at the rising edge could be neglected. The $G$ factor used in the fluorescence anisotropy measurements is measured by keeping the excitation polariser horizontal, and the polariser axes are then crossed, irrespective of the direction of the emission polariser. The relative intensities measured under these conditions were used to measure the $G$ factor. The steady-state fluorescence and time-resolved experiments were done at various temperatures ranging from 293 to $308 \mathrm{~K}$. 


\section{Results and discussion}

\subsection{Absorption and fluorescence}

Absorption spectra of ADR (1-5) dyes were recorded in glycerol. These dyes show three absorption maxima around 250, 275 and $394 \mathrm{~nm}$. The absorption maximum around $394 \mathrm{~nm}$ is assigned to the intramolecular charge transfer from the ring nitrogen to the ring carbonyl oxygen in the acridinedione fluorophore. The fluorescence spectra of ADR (1-5) dyes were obtained by exciting at both the wavelengths (394 and $250 \mathrm{~nm}$ ) and the emission maximum was observed around $460 \mathrm{~nm}$. Figure 1 gives the absorption and fluorescence spectrum of ADR (4) dye in glycerol.

\subsection{Steady state anisotropy}

The steady state excitation and emission anisotropy spectra of ADR dyes display the regions of negative and positive anisotropy. Excitation anisotropy is positive above $300 \mathrm{~nm}\left(S_{0} \rightarrow S_{1}\right)$ and negative below $300 \mathrm{~nm}\left(S_{0} \rightarrow S_{2}\right)$ (figure not shown). The constant emission anisotropy over the region $400-600 \mathrm{~nm}$ and the sharp fall in the excitation anisotropy below $300 \mathrm{~nm}$ is due to the involvement of higher energy electronic states. Emission anisotropy $(r)$ data for the same dye at different temperatures is collated in table 1. The plot of $r$ vs $\eta / T$ shows linear dependency (figure 2). $r$ values of ADR (1-5) dyes in glycerol are $0.29-0.33$ (table 1). This positive anisotropy suggests that the emission dipoles of ADR dyes at

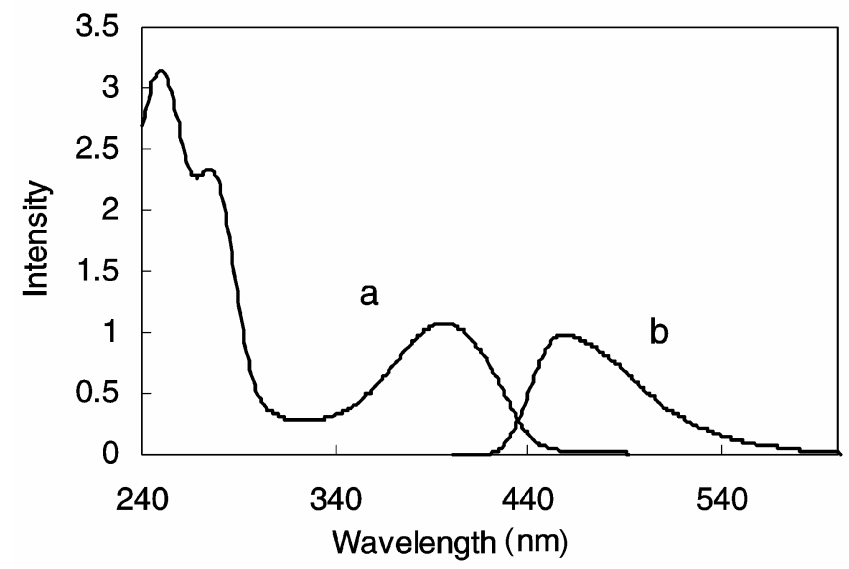

Figure 1. (a) Absorption spectrum of ADR (4) dye in glycerol. (b) Emission spectrum of ADR (4) dye in glycerol at $396 \mathrm{~nm}$ of excitation wavelength.
$460 \mathrm{~nm}$ are collinear with the absorption dipole at $394 \mathrm{~nm}$.

\subsection{Transition dipole directions}

Figure 3 shows the completely optimised geometry of the ADR (3) dye, predicted by hybrid HartreeFock/density functional theory method at B3LYP/6$31+\mathrm{G}^{*}$ level, using the Gaussian 03 software. ${ }^{33} \mathrm{Cal}-$ culations at B3LYP/6-31+G* level are reported to yield reliable results. ${ }^{34}$ The molecule belongs to $C_{2}$ point group, in agreement with the sofa conformation observed from crystallographic measurements. ${ }^{22}$ Vibrational frequency calculation confirmed that this structure is a minimum in the potential energy surface. The ADR (3) dye is about $0.5 \AA$ longer along its long axis $\left(\mathrm{C}_{5}---\mathrm{C}_{11}=7.649 \AA\right)$ than along its short axis $\left(\mathrm{C}_{8^{---}} \mathrm{C}_{18}=7 \cdot 147 \AA\right)$. It is seen that the short axis is collinear with the $C_{2}$ symmetry axis.

The transition dipole directions of ADR (1-5) dyes were extracted from the Cerius 2 Zindo software. The absorption transition dipole direction at $394 \mathrm{~nm}$ is directed along the short axis of the molecule and at $250 \mathrm{~nm}$ is directed along the long axis of the molecule and is shown in figure 3 for ADR (3) dye.

\subsection{Fluorescence lifetime studies}

Time-dependent fluorescence measurement shows single exponential decay for ADR dyes in glycerol with lifetime varying from 5 to $8 \mathrm{~ns}$ (table 1). The emission decay profile of ADR (3) dye in glycerol recorded at $460 \mathrm{~nm}$ is shown in figure 4 .

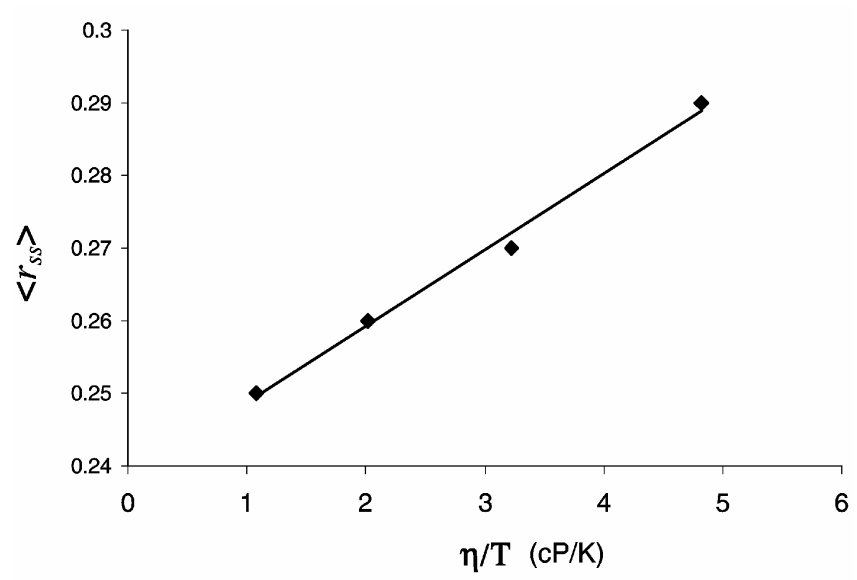

Figure 2. Plot of $r$ vs $\eta / T$ for ADR (3) dye in glycerol. 
Table 1. Fluorescence lifetimes, emission anisotropy and decay parameters of ADR (1-5) dyes in glycerol at different temperatures, extracted at two excitation wavelengths.

\begin{tabular}{|c|c|c|c|c|c|c|c|c|c|c|}
\hline \multirow[b]{2}{*}{ ADR } & \multirow[b]{2}{*}{$\tau_{f}(\mathrm{~ns})$} & \multirow[b]{2}{*}{$T(\mathrm{~K})$} & \multirow{2}{*}{$\begin{array}{c}<r_{s s}> \\
\lambda_{\mathrm{ex}} 394 \mathrm{~nm} \\
\lambda_{\mathrm{em}} 460 \mathrm{~nm}\end{array}$} & \multicolumn{2}{|c|}{$\begin{array}{l}\text { Single exponential } \\
\lambda_{\mathrm{ex}}(250 \mathrm{~nm})\end{array}$} & \multicolumn{5}{|c|}{ Bi-exponential $\lambda_{\mathrm{ex}}(394 \mathrm{~nm})$} \\
\hline & & & & $\tau_{r}(\mathrm{~ns})$ & $B 1$ & $\tau_{r 1}$ & (ns) (rel. amp) & $B 1$ & $\tau_{r 2}(\mathrm{~ns})($ rel. amp $)$ & $B 2$ \\
\hline \multirow[t]{4}{*}{1} & $8 \cdot 03$ & 293 & $0 \cdot 30$ & $26 \cdot 8$ & $-0 \cdot 19$ & & $1.04(0 \cdot 37)$ & 0.03 & $26 \cdot 8(99 \cdot 63)$ & $0 \cdot 35$ \\
\hline & & 298 & $0 \cdot 28$ & $16 \cdot 3$ & $-0 \cdot 16$ & & $0.25(0.37)$ & 0.08 & $16 \cdot 2(99 \cdot 63)$ & $0 \cdot 33$ \\
\hline & & 303 & $0 \cdot 25$ & $10 \cdot 9$ & $-0 \cdot 16$ & & $0 \cdot 11(0 \cdot 66)$ & 0.05 & $10 \cdot 9(99 \cdot 34)$ & $0 \cdot 33$ \\
\hline & & 308 & $0 \cdot 24$ & $6 \cdot 20$ & $-0 \cdot 15$ & & $0.06(0.61)$ & 0.08 & $6 \cdot 19(99 \cdot 39)$ & $0 \cdot 32$ \\
\hline \multirow[t]{4}{*}{2} & $5 \cdot 00$ & 293 & $0 \cdot 30$ & $11 \cdot 6$ & $-0 \cdot 07$ & & $0.7(0 \cdot 10)$ & $0 \cdot 04$ & $11.6(99.90)$ & $0 \cdot 27$ \\
\hline & & 298 & $0 \cdot 24$ & $10 \cdot 6$ & $-0 \cdot 08$ & & $0 \cdot 3(0 \cdot 16)$ & $0 \cdot 02$ & $10.6(99.84)$ & $0 \cdot 28$ \\
\hline & & 303 & 0.23 & $7 \cdot 36$ & -0.08 & & $0.15(0.09)$ & 0.01 & 7.35 (99.91) & $0 \cdot 29$ \\
\hline & & 308 & $0 \cdot 21$ & $4 \cdot 63$ & $-0 \cdot 08$ & & $0.08(0.03)$ & 0.07 & $4.63(99.97)$ & 0.29 \\
\hline \multirow[t]{4}{*}{3} & $6 \cdot 45$ & 293 & $0 \cdot 29$ & $21 \cdot 8$ & $-0 \cdot 13$ & & $0.49(0 \cdot 19)$ & 0.02 & $21.8(99.81)$ & $0 \cdot 25$ \\
\hline & & 298 & $0 \cdot 28$ & $18 \cdot 5$ & $-0 \cdot 13$ & & $0.48(0.29)$ & 0.02 & $18.5(99.71)$ & $0 \cdot 25$ \\
\hline & & 303 & $0 \cdot 26$ & $11 \cdot 5$ & $-0 \cdot 11$ & & $0.25(0.13)$ & 0.01 & $11.5(99.87)$ & $0 \cdot 23$ \\
\hline & & 308 & $0 \cdot 25$ & $8 \cdot 71$ & $-0 \cdot 12$ & & $0 \cdot 17(0 \cdot 12)$ & 0.01 & $8.69(99.88)$ & $0 \cdot 23$ \\
\hline \multirow[t]{4}{*}{4} & $8 \cdot 0$ & 293 & $0 \cdot 33$ & $28 \cdot 7$ & $-0 \cdot 11$ & & $1.67(0.40)$ & 0.02 & $28.7(99 \cdot 60)$ & $0 \cdot 28$ \\
\hline & & 298 & $0 \cdot 31$ & $23 \cdot 7$ & $-0 \cdot 10$ & & $1.46(0.07)$ & 0.03 & $23 \cdot 7(99 \cdot 30)$ & $0 \cdot 28$ \\
\hline & & 303 & $0 \cdot 29$ & 19.7 & $-0 \cdot 11$ & & $0.08(0.55)$ & 0.02 & $19.7(99.45)$ & $0 \cdot 27$ \\
\hline & & 308 & $0 \cdot 27$ & $13 \cdot 6$ & $-0 \cdot 11$ & & $0.02(0.02)$ & 0.02 & $13 \cdot 6(99.98)$ & $0 \cdot 20$ \\
\hline \multirow[t]{4}{*}{5} & $6 \cdot 96$ & 293 & $0 \cdot 32$ & $22 \cdot 7$ & $-0 \cdot 10$ & & $0.43(0.15)$ & 0.02 & $22.7(99.85)$ & $0 \cdot 25$ \\
\hline & & 298 & $0 \cdot 29$ & $18 \cdot 8$ & $-0 \cdot 13$ & & $0.35(0 \cdot 19)$ & 0.02 & $18.8(99.81)$ & $0 \cdot 26$ \\
\hline & & 303 & 0.26 & $13 \cdot 2$ & $-0 \cdot 15$ & & $0 \cdot 31(0 \cdot 17)$ & 0.01 & $13 \cdot 3(99 \cdot 83)$ & 0.24 \\
\hline & & 308 & $0 \cdot 23$ & $9 \cdot 86$ & $-0 \cdot 14$ & & $0 \cdot 10(0 \cdot 12)$ & 0.01 & $9.84(99.88)$ & $0 \cdot 23$ \\
\hline
\end{tabular}

Decay curves with 10000 counts at the maximum, $\chi^{2}=1 \cdot 1,<r_{s S}>=$ steady state anisotropy at excitation (394 $\mathrm{nm}$ ) and emission (460 $\mathrm{nm})$
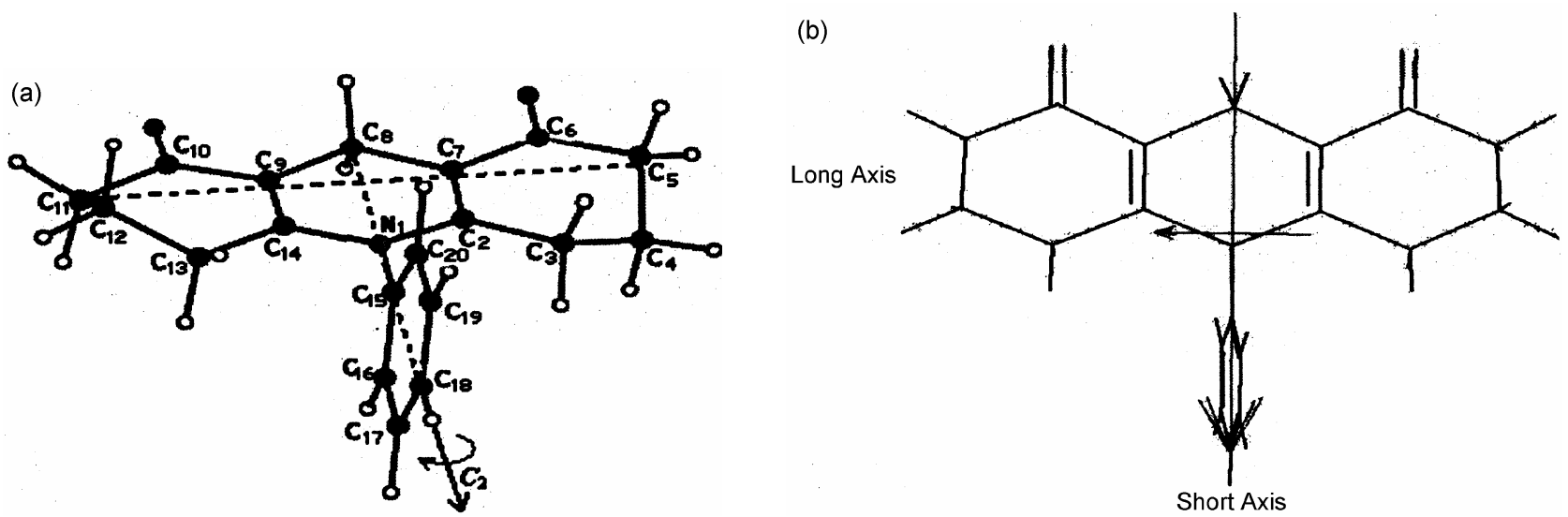

Figure 3. (a) B3LYP/6-31+G* optimised geometry of $\mathrm{ADR}(3) . \mathrm{C}_{5}--\mathrm{C}_{11}=7 \cdot 649 \AA$ (long axis); $\mathrm{C}_{8}---\mathrm{C}_{18}=7 \cdot 147 \AA$ (short axis); $\mathrm{C}_{9} \mathrm{C}_{10} \mathrm{C}_{11} \mathrm{C}_{12}=29.5^{\circ}\left[30 \cdot 3^{\circ}\right] ; \mathrm{C}_{11} \mathrm{C}_{12} \mathrm{C}_{13} \mathrm{C}_{14}=50 \cdot 3^{\circ}\left[43.5^{\circ}\right]$; experimental values inside square brackets are for the acridinedione derivative (not shown in the figure) reported in ref. [32]. (b) Absorption transition dipole directions at 250 and $394 \mathrm{~nm}$ for ADR (3) dye.

\subsection{Time-resolved fluorescence anisotropy decay of ADR dyes in glycerol}

The fluorescence anisotropy decays were recorded at $460 \mathrm{~nm}$ with excitation at 250 and $394 \mathrm{~nm}$. Fluorescence anisotropy $r(t)$ is calculated using (3) and the decay profiles obtained on excitation at two extremes of transition moment, i.e. at 250 and $394 \mathrm{~nm}$ are presented in figure 5. The fluorescence anisotropy decay is biexponential on excitation at $394 \mathrm{~nm}$ while it is single exponential when excited at $250 \mathrm{~nm}$. 
The fluorescence anisotropy decay for ADR (3) dye in glycerol is $21.80 \mathrm{~ns}(293 \mathrm{~K})$ at $250 \mathrm{~nm}$ and the data are shown in table 1 for other dyes. At this wavelength of excitation, the absorption and emission dipoles are nearly perpendicular (scheme 1) and

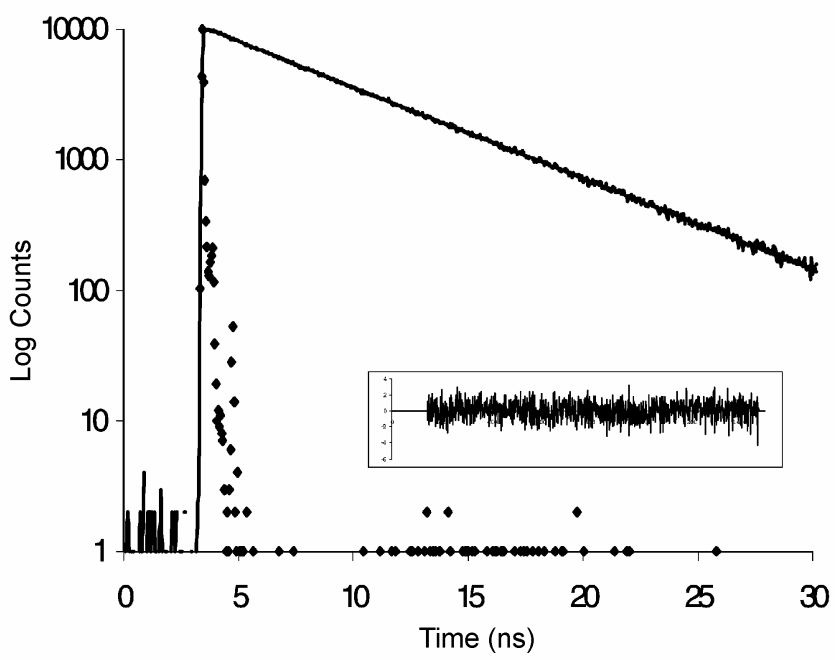

Figure 4. Fluorescence lifetime decay of ADR (3) dye in glycerol at $293 \mathrm{~K}$, results (residuals) for single exponential fit are shown.
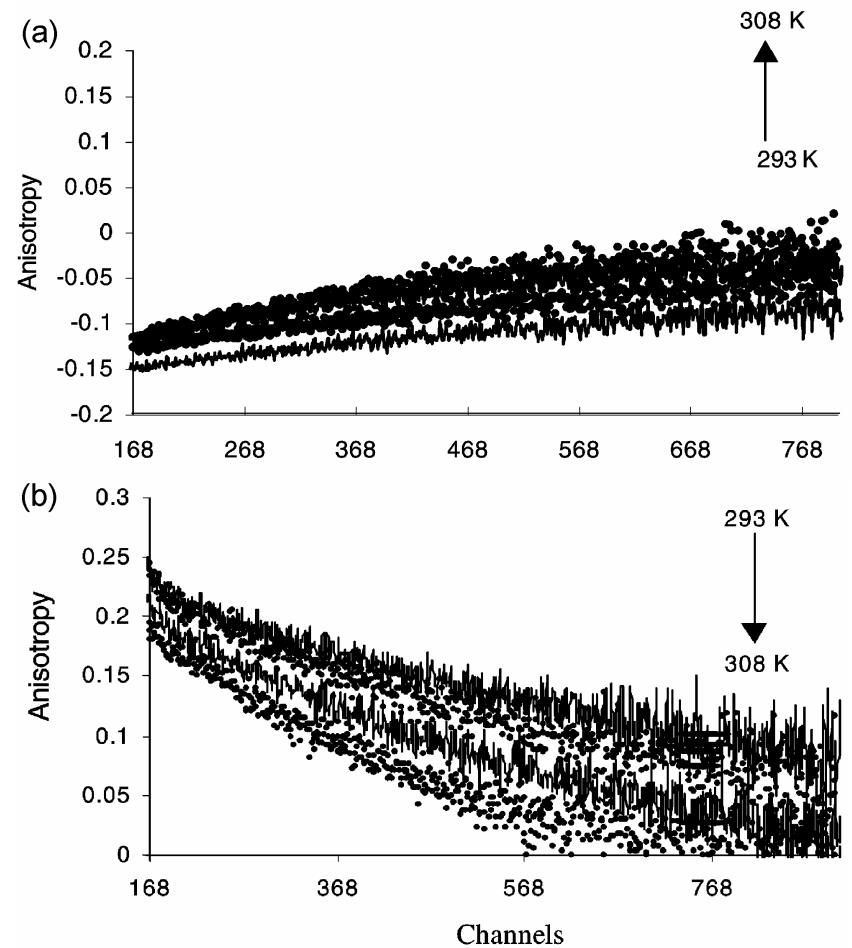

Figure 5. Fluorescence anisotropy decay of ADR (3) dye in glycerol from 293 to $308 \mathrm{~K}$ recorded at $460 \mathrm{~nm}$ excitation at (a) $250 \mathrm{~nm}$ (negative anisotropy) and (b) $394 \mathrm{~nm}$ (positive anisotropy). shows a negative fluorescence anisotropy (figure 5). Figure 5 demonstrates the decay behaviour of ADR (3) dye, that clearly reveals the initial fall in fluorescence anisotropy decay which then approaches zero.

Rotation along the $y$-axis displaces the transition moment along the $z$-axis, which causes depolarisation and results in one in-plane rotation. Two out-ofplane rotations along the $x$-axis and $z$-axis do not displace the transition moments. This can be compared with the fluorescence anisotropy decay of perylene, which shows fast in-plane rotation and slower outof-plane rotation. ADR dyes show single exponential fluorescence anisotropy decay at $250 \mathrm{~nm}$ due to slower in-plane rotation.

The absorption and emission dipoles are nearly collinear at $394 \mathrm{~nm}$ (scheme 2) and show positive fluorescence anisotropy (figure 5).

The fluorescence anisotropy decay time of ADR (3) is $0.49 \mathrm{~ns}$ and $21.80 \mathrm{~ns}$ at $293 \mathrm{~K}$ (table 1). The longer fluorescence anisotropy decay time $(21.80 \mathrm{~ns})$ is the same as that of the fluorescence anisotropy decay time when ADR (3) dye is excited at $250 \mathrm{~nm}$ absorption band, which is assigned to the in-plane

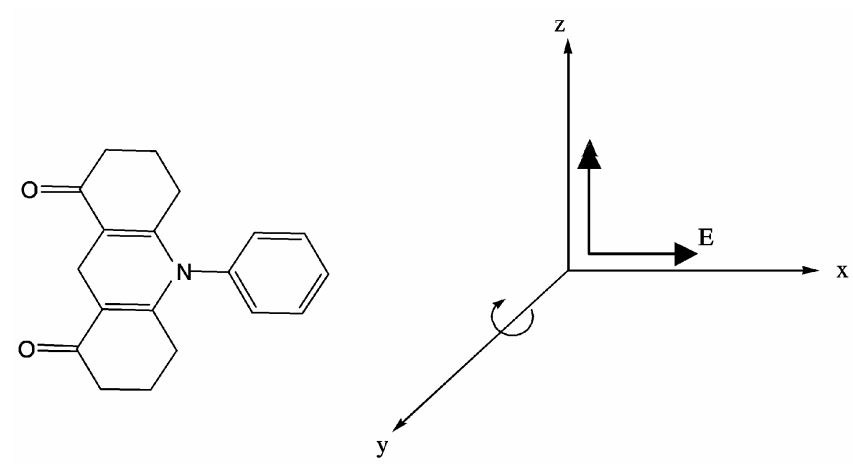

Scheme 1.<smiles>O=C1CCCC2=C1CC1=C(CCCC1=O)N2c1ccccc1</smiles>

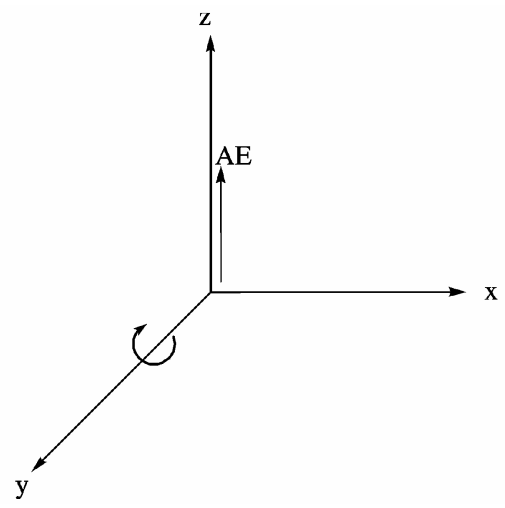

Scheme 2. 
Table 2. The angular orientation of the absorption and emission dipoles $\left(\theta_{\mathrm{AE}}\right)$ and the diffusion coefficients of ADR (1-5) dyes in glycerol at different temperatures.

\begin{tabular}{|c|c|c|c|c|c|}
\hline $\mathrm{ADR}$ & $\theta_{\mathrm{AE}}$ at $250 \mathrm{~nm}$ & $\theta_{\mathrm{AE}}$ at $394 \mathrm{~nm}$ & $T(\mathrm{~K})$ & $D_{\|} \times 10^{-9}\left(\mathrm{~s}^{-1}\right)$ & $D_{\perp} \times 10^{-9}\left(\mathrm{~s}^{-1}\right)$ \\
\hline 1 & $74^{\circ}$ & $20^{\circ}$ & $\begin{array}{l}293 \\
298 \\
303 \\
308\end{array}$ & $\begin{array}{l}0.0062 \\
0 \cdot 0103 \\
0 \cdot 0152 \\
0 \cdot 0270\end{array}$ & $\begin{array}{l}0 \cdot 2374 \\
0 \cdot 9948 \\
2 \cdot 2650 \\
4 \cdot 1540\end{array}$ \\
\hline 2 & $63^{\circ}$ & $26^{\circ}$ & $\begin{array}{l}293 \\
298 \\
303 \\
308\end{array}$ & $\begin{array}{l}0.0144 \\
0.0157 \\
0.0227 \\
0.0298\end{array}$ & $\begin{array}{l}0.3503 \\
0 \cdot 8250 \\
1 \cdot 6554 \\
3 \cdot 3101\end{array}$ \\
\hline 3 & $68^{\circ}$ & $30^{\circ}$ & $\begin{array}{l}293 \\
298 \\
303 \\
308\end{array}$ & $\begin{array}{l}0.0076 \\
0 \cdot 0090 \\
0.0145 \\
0.0192\end{array}$ & $\begin{array}{l}0.5060 \\
0.5163 \\
0.9930 \\
1.4610\end{array}$ \\
\hline 4 & $67^{\circ}$ & $28^{\circ}$ & $\begin{array}{l}293 \\
298 \\
303 \\
308\end{array}$ & $\begin{array}{l}0.0058 \\
0 \cdot 0070 \\
0 \cdot 0116 \\
0.0122\end{array}$ & $\begin{array}{l}0 \cdot 1468 \\
0 \cdot 1678 \\
3 \cdot 1190 \\
12 \cdot 490\end{array}$ \\
\hline 5 & $70^{\circ}$ & $31^{\circ}$ & $\begin{array}{l}293 \\
298 \\
303 \\
308\end{array}$ & $\begin{array}{l}0.0073 \\
0 \cdot 0089 \\
0 \cdot 0125 \\
0.0170\end{array}$ & $\begin{array}{l}0.5780 \\
0.7113 \\
0 \cdot 8002 \\
2 \cdot 4915\end{array}$ \\
\hline
\end{tabular}

rotation. Rotation along the $y$-axis results in one inplane rotation. Rotation along the $x$-axis and the $z$ axis results in two out-of-plane rotations, in which the $x$-axis contributes to the depolarisation. ADR dyes show biexponential fluorescence anisotropy decay due to faster out-of-plane and slower in-plane rotations. The biexponential analysis of ADR dyes in glycerol were carried out by fixing the decay time obtained at $250 \mathrm{~nm}$ to extract the fluorescence anisotropy decay time at $394 \mathrm{~nm}$ and are collated in table 1 for various temperatures. Barkley et $a l^{16}$ interpreted the rotational dynamics of a planar molecule 9 -aminoacridine, in terms of prolate ellipsoid of revolution. In 9-aminoacridine, the transition moment at $430 \mathrm{~nm}$ is along the long axis of the molecule and at $260 \mathrm{~nm}$ along the short axis of the molecule. The authors confirmed the prolate model based on the following observations: (i) the decay of the emission anisotropy is biexponential at $430 \mathrm{~nm}$ and monoexponential at $260 \mathrm{~nm}$, and (ii) the values of $\tau_{r(430 \mathrm{~nm})}$ are less than those at $\tau_{r(260 \mathrm{~nm})}$. A similar observation in the present investigation suggests that the ADR dyes rotate as prolate models of ellipsoids. In the present study, we find the faster out-of-plane rotation in contrast to the earlier reports ${ }^{7-14,16}$ for the following reasons. The calculated lengths of the long and short axes of the ADR molecule change on changing the substituent. This change in substituent does not play any role in the faster out-of-plane rotation, instead the sofa and boat conformation of the ADR molecule makes it undergo faster out-of-plane rotation, followed by slower in-plane rotation.

The angles between the absorption and emission dipoles were calculated for ADR dyes using (4) below and are collated in table 2. The $r_{0}$ value is lower than the theoretical values that range between $-0 \cdot 2$ and $+0 \cdot 4$.

$$
r_{0}=0 \cdot 2\left(3 \cos ^{2} \theta-1\right) .
$$

\subsection{Diffusion coefficients of ADR dyes in glycerol}

The theory of non-spherical molecules is usually described in terms of prolate and oblate ellipsoids. The anisotropy decay of an ellipsoid of revolution can display two or three correlation times, which are the functions of two rotational diffusion coefficients $\left(D_{\|}\right.$ and $D_{\perp}$ ). The rotational correlation times are functions of rotational diffusion coefficients ${ }^{35}$ as shown below:

$$
\begin{aligned}
& \tau_{r 1}^{-1}=6 D_{\perp}, \\
& \tau_{r 2}^{-1}=2 D_{\perp}+4 D_{\|}, \\
& \tau_{r 3}^{-1}=5 D_{\perp}+D_{\|} .
\end{aligned}
$$



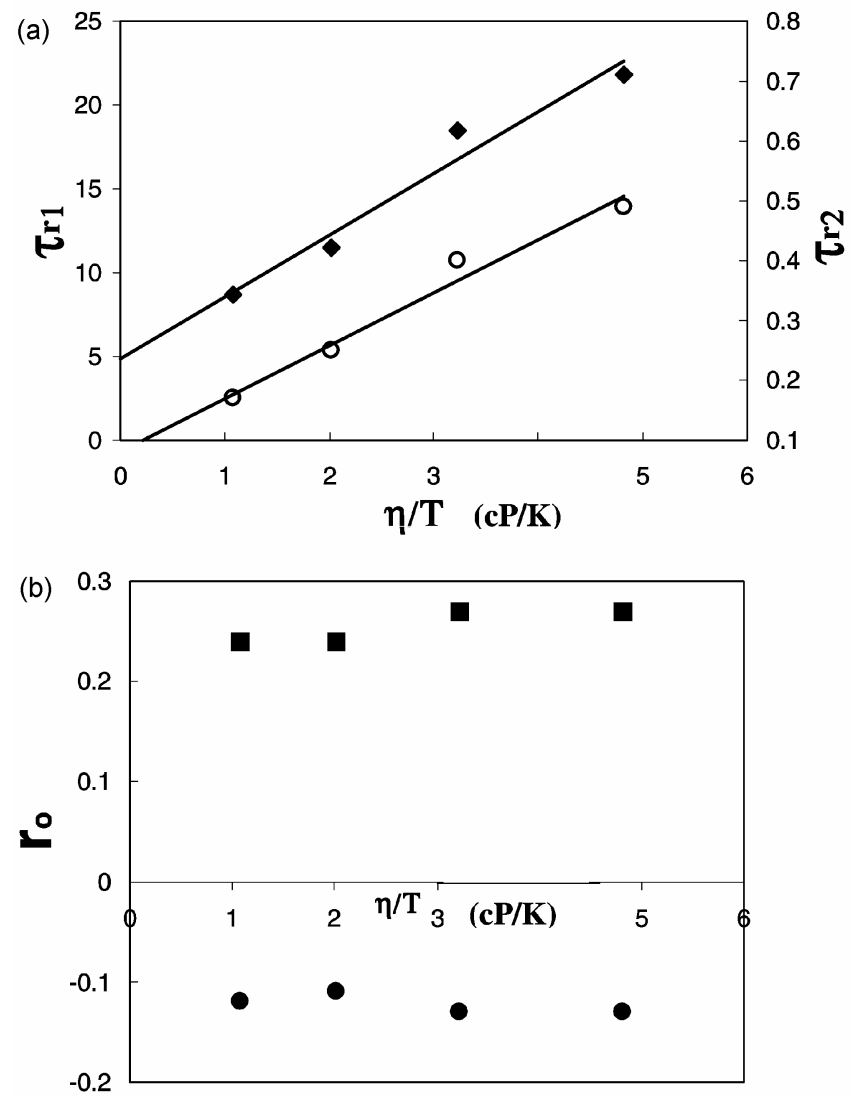

Figure 6. The dependence of rotational correlation time and pre-exponential factors for ADR (3) dye on viscosity and temperature: (a) Plots of ( $\boldsymbol{\square}) \tau_{r 1}$ vs $\eta / T$ and (O) $\tau_{r 2}$ vs $\eta / T$; (b) plots of $r_{0} \mathrm{vs} \eta / T$, ( $)$ at $394 \mathrm{~nm}$ (positive anisotropy) and $(\bullet)$ at $250 \mathrm{~nm}$ (negative anisotropy).

The diffusion coefficients $D_{\|}$and $D_{\perp}$ calculated from the rotational correlation times for ADR (1-5) dyes in glycerol are presented in table 2. The data show that the value of $D_{\perp}$ is lower than that of $D_{\|}$, which is dependent on temperature. This is because the rotation about the long axis occurs with less displacement of solvent molecules when compared to rotation about the short axis.

\subsection{Temperature-dependence of ADR dyes in glycerol}

The plots of $\eta / T$ vs rotational correlation time and $\eta / T$ vs pre-exponential factors for the ADR (3) dye are shown in figure 6 . Figure 6 a reveals that rotational correlation time depends linearly on $\eta / T$, whereas figure $6 \mathrm{~b}$ shows that the pre-exponential factors are independent of $\eta / T$. The strong dependence of $\tau_{r 1}$ and $\tau_{r 2}$ on $\eta / T$ reveals the strong anisotropic rotation of ADR dyes.

\section{Conclusion}

In conclusion, the rotational time of ADR (1-5) dyes in glycerol were recorded at different temperatures using the time-resolved fluorescence technique, which are modelled as prolate ellipsoids. Interestingly, the decay of the ADR dyes exhibits the two-correlation system at short axis and the pre-exponential factors are independent of temperature and viscosity, while the rotational correlation times are dependent on temperature and viscosity. In our subsequent studies, we show how this study helps in understanding the dynamical changes in aqueous solutions of ADR molecules in $\beta$-CD nanocavity.

\section{Acknowledgements}

We gratefully acknowledge grants from the Council of Scientific and Industrial Research and Department of Science and Technology-IRPHA, New Delhi. We also thank Dr E J Padma Malar of the University of Madras for B3LYP/6-31+G* optimised geometry.

\section{References}

1. Fleming G R 1986 Chemical applications of ultrafast spectroscopy (New York: Oxford University Press); Dorfmüller Th and Pecora R (eds) 1987 Rotational dynamics of small and macromolecules (New York: Springer-Verlag)

2. Reiser D and Laubereau A 1982 Opt. Commun. 42 329

3. Huntress W J Jr $1970 A d v$. Magn. Reson. 41

4. Goldman S A, Bruno G V, Polnaszek C F and Freed J H 1972 J. Chem. Phys. 56716

5. Vold S L, Vold R R, and Canet D 1977 J. Chem. Phys. 661202

6. Zinsli P E 1977 Chem. Phys. 20299

7. Chuang T J and Eisenthal K B 1971 Chem. Phys. Lett. 11368

8. Phillion D W, Kuizenga D J and Siegman A E 1975 Appl. Phys. Lett. 2785

9. Fleming G R, Morris J M and Robinson G W 1976 Chem. Phys. 1791

10. Mantulin W W and Weber G 1977 J. Chem. Phys. 66 4092

11. Spears K G and Cramer L E 1978 Chem. Phys. 301

12. Von Jena A and Lessing H E 1981 Chem. Phys. Lett. 78187

13. Bauer D R, Brauman J I and Pecora R $1974 \mathrm{~J}$. Am. Chem. Soc. 966840

14. Kivelson D and Madden P A 1980 Annu. Rev. Phys. Chem. 31523

15. Eisenthal K B and Drexhage K H 1969 J. Chem. Phys. 515720 
16. Barkley M D, Kowalczyk A A and Brand L $1981 \mathrm{~J}$. Chem. Phys. $\mathbf{7 5} 3581$

17. Vyleta N P, Coley A L and Laws W R 2004 J. Phys. Chem. A108 5156

18. Truong T V and Shen Y R 2005 J. Chem. Phys. 122 091104

19. Duschl J, Michl M and Kunz W 2004 Angew. Chem. Int. Ed. 43634

20. Chou S H and Wirth M J 1989 J. Phys. Chem. 93 7694

21. Visser A J W G, Vos K, van Hoek A and Santema J S J. Phys. Chem. 92759

22. Sivaraman J, Subramanian K, Velmurugan D, Subramanian E and Ramakrishnan V T 1994 Acta Crystal$\log r$. C50 2011

23. Murugan $P$, Shanmugasundaram $P$, Ramakrishnan V T, Venkatachalapathy B, Srividya N, Ramamurthy P, Gunasekaran K and Velmurugan D $1998 \mathrm{~J}$. Chem. Soc., Perkin Trans. 2999

24. Singh S, Chhina S, Sharma V K and Sachdev S S 1982 J. Chem. Soc., Chem. Commun. 453
25. Srividya N, Ramamurthy $P$, Shanmugasundaram $P$ and Ramakrishnna V T 1996 J. Org. Chem. 615083

26. Srividya N, Ramamurthy $P$ and Ramakrishnan V T 1998 Spectrochim. Acta $\mathbf{5 4} 245$

27. Venkatachalapathy B and Ramamurthy P 1999 Phys. Chem. Chem. Phys. 12223

28. Indirapriyadharshini V K, Karunanithi $\mathrm{P}$ and Ramamurthy P 2001 Langmuir 174056

29. Thiagarajan V, Selvaraju C, Padmamalar E J and Ramamurthy P 2004 Chem. Phys. Chem. 51200

30. Lakowicz J R 1999 Principle of fluorescence spectroscopy 2nd edn (New York: Plenum)

31. O'Connor D V and Phillips D 1984 Time correlated single photon counting (London: Academic Press)

32. Jeyakanthan J et al 2002 Crystallogr. Res. Technol. 371029

33. Frisch M J et al 2004 Gaussian '03, Revision B.04 Gaussian, Inc., Wallingford, CT

34. Foresman J B and Frish A 1996 Exploring chemistry with electronic structure methods (Pittsburgh, PA: Gaussian)

35. Tao T 1969 Biopolymers 8609 